\title{
IMPROVEMENT OF FLEXIBLE ROTOR/ACTIVE MAGNETIC BEARINGS SYSTEM PERFORMANCE USING PI-D CONTROL
}

\author{
Adis J. Muminovic $^{{ }^{*}}$ - Sanjin Braut ${ }^{2}$ - Adil Muminovic ${ }^{1}$ - Isad Saric ${ }^{1}$ - Goranka Stimac Roncevic ${ }^{2}$ \\ ${ }^{1}$ Department of Mechanical Design, Faculty of Mechanical Engineering, University of Sarajevo, Vilsonovo setaliste no. \\ 9. 71000 Sarajevo, Bosnia and Herzegovina \\ ${ }^{2}$ Department of Engineering Mechanics, Faculty of Engineering, University of Rijeka, Vukovarska no. 58. 51000 Rijeka, \\ Croatia
}

\begin{tabular}{l}
\hline ARTICLE INFO \\
\hline Article history: \\
Received: 27.5 .2019$. \\
Received in revised form: 9. 7. 2019. \\
Accepted: 16.7 .2019$. \\
\hline Keywords: \\
Active magnetic bearings \\
Flexible rotor \\
PID \\
PI-D \\
\hline DOI: http://doi.org/10.30765/er.40.2.12
\end{tabular}

\section{Introduction}

From the very beginning of rotating elements' existence, from wooden shafts for water mills up to modern rotating elements, there has been a problem with rotor and stator contact. Because of that contact a lot of problems occur; problems which have not been completely solved yet. Some of these problems are friction and wear between moving and static surfaces, limited rotating speed, occurrence of high temperature, vibration etc. The first solution to these problems was the use of lubrication between rotor and stator. As a result of this idea, modern journal

\begin{abstract}
:
Proportional-integral-derivative (PID) control is the most common control approach used to control active magnetic bearings system, especially in the case of supporting rigid rotors. In the case of flexible rotor support, the most common control is again PID control in combination with notch filters. Other control approaches, known as modern control theory, are still in development process and cannot be commonly found in real life industrial application. Right now, they are mostly used in research applications. In comparison to PID control, PI-D control implies that derivate element is in feedback loop instead in main branch of the system. In this paper, performances of flexible rotor/active magnetic bearing system were investigated in the case of PID and PI-D control, both in combination with notch filters. The performances of the system were analysed using an analysis in time domain by observing system response to step input and in frequency domain by observing a frequency response of sensitivity function.
\end{abstract}

bearings have been invented. The second idea was a revolution for these problems; it refers to replacing sliding friction with rotating friction by placing additional rotating element (mostly in the shape of small balls) between the rotor and the stator. As a result of this idea, later on, modern roller bearings have been invented. Roller bearings are nowadays, the most commonly used technology, for rotating element support. Journal and roller bearings are often used today, but they still do not solve all the above mentioned problems completely; they still have some disadvantages: they do not entirely eliminate friction, they still need lubrication and sealing, they have limitation for operations on high temperatures and

\footnotetext{
* Corresponding author. Tel.: 0038761921 772; fax: 0038733729808

E-mail address: adis.muminovic@mef.unsa.ba
} 
high rotational speed. Because of the abovementioned disadvantages there is a need to try a completely separate rotor and stator.

The only technology known so far, which can support the rotor and at the same time completely separate the rotor and the stator is the technology of AMB. AMB has a lot of advantages in comparison to classical roller and journal bearings: they eliminate friction, lubrication and sealing completely, can run at very high speeds, have wide range of temperature application, are especially suitable for vacuums application, and can be used to control vibration of the rotor and stiffness of the bearings. AMB has been a subject of research for about two decades. The research is usually divided on the research of rigid rotor support using AMB and the research of flexible rotor support using $\mathrm{AMB}$. In the beginning of $\mathrm{AMB}$ research in 1970s and 1980s, the main goal was always to design such controller which will have as less as calculation as possible, because computers did not have the performance they have today. According to [1] the first authors to carry out research about the active control of AMB were Schweitzer, Bleuler, Salm and Herzog. According to [2] and [3] the first paper about active control of AMB was by Schweitzer [1]. Salm and Schweitzer elaborated how to use reduced models of rotors for control system design in a closed loop [4]. Bleuler designed the method for PD (proportional - derivate) controller design for rigid rotors [5]. Salm was the first author to introduce the procedure to design controller for flexible rotor with collocation and give stability margins for linear time invariable control. Herzog noticed that in Salm's paper, there is a special case of passive control which has a questionable stability in the case of digital implementation. Herzog is the first author to start research with $\mathrm{H}$ infinity control of AMB.

In 1990s, the authors who stood out in the area of AMB research were Larsonneur, Gähler, Fujita, Cui, Namerikawa, Yamashita, Fittro, Knosp, Lösch and Schönhoff. Larsonneur developed SPOC-D algorithm for low order digital controller design [6]. This algorithm can be used for flexible rotor control where it shows better performance than PID control but cannot take in consideration gyroscopic effect. Gähler worked on research to design a controller for high flexibility rotor with a high gyroscopic effect and non-collocation. He developed a computer application for a controller design using a transfer function phase shaping by moving its poles [7].
$\mathrm{H}$ infinity and $\mu$ synthesis, also known as modern control methods, have been used on AMB by several authors [8-11].

Last year's focus of research was transferred from rigid rotor/AMB system to flexible rotor/AMB system. The stability of these systems cannot be achieved by using just classical PID control. Most common control approach is to add notch filters which can prevent appearance of flexible forms of vibration. To design appropriate controller for flexible rotor control using AMB, it is necessary to be familiar with the behaviour of a flexible rotor in the area of critical speeds. To be precise, it is necessary to find out frequencies on which flexible mode of vibration and critical speeds appear. This can be done by using some of the numerical methods. In this research, the finite element method was used. This method is the reason why mechanical engineers are becoming more and more interested in this area of research.

Beside the above mentioned issues, flexible rotor/AMB systems have another problem: the noncollocation of actuator and sensor. Non-collocation means that sensor and actuator are displaced along the rotor axial axis. This is especially a problem in the case when modal node is located between the actuator and sensor axes. Flexible rotor/AMB system represents a classical mechatronic system where the controller can be considered as a part of the system. Designing a controller for this system is a very complicated process. Because of that, in the last few decades, a lot of research has been done in order to find out the best way to design a proper controller for the flexible rotor control using AMB [3 - 5] and [12]. Also, tuning of PID control parameters is in the focus of research right now [13, 14]. Reviewing the literature it can be noticed that there is no research which focuses on different types of PID control used to control flexible rotor/AMB system. In this paper, a different form of PID control (PI-D control, derivate in feedback loop) is used to control flexible rotor/AMB system.

Both controllers (PID and PI-D) employed in the system include notch filters for flexible mode stabilization. In the second chapter, a mathematical model of the flexible rotor with non-collocation supported by two radial active magnetic bearings is presented. Implemented controllers are presented in the third chapter. The numerical model, developed in Matlab/Simulink, is presented in chapter four. In chapter five, the results of the performances analysis of the system, for both implemented controllers, are presented. 


\section{Mathematical model of the flexible rotor/AMB system}

The first step in the procedure of numerical modelling of the flexible rotor/AMB system is to obtain a flexible rotor model. Generally speaking, the flexible rotor is considered to be a continuum, where the position of each of its points (in time and space) can be mathematically described by partial differential equations. Since analytical solutions of such equations can be found only for simple examples, numerical approaches are usually applied. In this research, finite element method (FEM) is used. To model the system as a linear one and to observe the dynamic behaviour of the flexible rotor separately in axial and radial directions, the following assumptions were considered: (i) the rotor is axisymmetric, (ii) the rotor displacements are small compared with rotor geometry, (iii) all the parameters of the system are time-invariant, (iv) the rotational speed is considered constant, (v) torsional vibrations and axial displacements are neglected, (vi) sensors and actuators are connected to the discrete points of the rotor. Flexible rotor which meets the above mentioned assumptions can be modelled by Euler Bernoulli beam theory. Beam elements are connected by nodes each having two translational $\left(u_{i}\right.$ and $\left.v_{i}\right)$ and two rotational $\left(\alpha_{i}\right.$ and $\left.\beta_{i}\right)$ degrees of freedom (Fig. 1.).

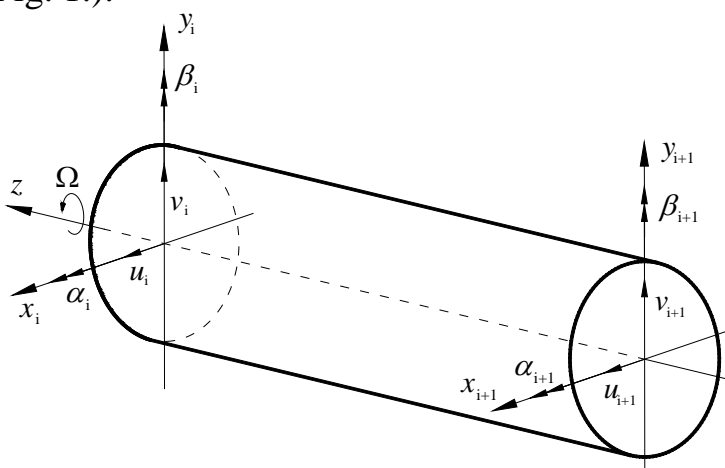

Figure 1. Beam finite element for the analysis of flexible rotor

The equation of the motion of the entire system can be presented as:

$$
\mathbf{M} \ddot{\mathbf{q}}+(\mathbf{C}+\Omega \mathbf{G}) \dot{\mathbf{q}}+\mathbf{K q}=\mathbf{f},
$$

where $\mathbf{M}$ is the global symmetrical mass matrix which includes flexible shaft and attached discs, $\mathbf{C}$ is the global symmetrical damping matrix, $\Omega$ is the rotational speed, $\mathbf{G}$ is the global skew-symmetrical gyroscopic effect matrix, $\mathbf{K}$ is the global symmetrical stiffness matrix, $\mathbf{f}$ is the force vector and $\mathbf{q}$ is the global displacement vector defined as:

$$
\mathbf{q}=\left[u_{1} v_{1} \alpha_{1} \beta_{1} u_{2} v_{2} \alpha_{2} \beta_{2} \ldots u_{N} v_{N} \alpha_{N} \beta_{N}\right]^{T}
$$

where $\mathrm{N}$ is the number of nodes. In the second step, the modelling of AMBs is carried out. Each AMB consists of an electromagnet with eight electromagnetic poles, i.e. it has four pairs of poles placed at an angle of $\pm 45^{\circ}$ in relation to the vertical $y$ axis. The influence of AMBs on the rotor is modelled by linear forces defined for one AMB as follows:

$$
\mathbf{f}=\mathbf{K}_{\mathbf{S}} \mathbf{q}+\mathbf{K}_{\mathbf{i}} \mathbf{i}
$$

where $\mathbf{i}$ is the current vector, $\mathbf{K}_{\mathbf{S}}$ and $\mathbf{K}_{\mathbf{i}}$ are the matrixes of the force-displacement coefficients $k_{s}$ and the force-current coefficients $k_{i}$, related to translational degrees of freedom of the nodes in which the forces are attached. The displacement vector of the actuator locations $\mathbf{q}_{\mathbf{a}}$ and the displacement vector of the sensor locations $\mathbf{q}_{\mathbf{s}}$ are described in terms of the vector $\mathbf{q}$ as:

$$
\begin{aligned}
& \mathbf{q}_{\mathbf{a}}=\mathbf{T}_{\mathbf{a}} \mathbf{q} \\
& \mathbf{q}_{\mathbf{s}}=\mathbf{T}_{\mathbf{s}} \mathbf{q}
\end{aligned}
$$

where $\mathbf{T}_{\mathbf{a}}$ and $\mathbf{T}_{\mathbf{s}}$ are the transformation matrixes. The colocation and the non-colocation of the sensor and actuator axes are modelled by choosing the nodes of sensor and actuator locations in order to obtain the displacement vector at the same node where the actuator force is applied (colocation) or to obtain the displacement vector at some axially displaced node (non-colocation). The detailed modelling procedure can be found in [1]. In order to design the control algorithm for the analysed rotor/AMB system the equation (1) is converted to its state space representation.

Also, the model decomposition and the model truncation methods are applied and only the lower order modes relevant for the dynamic behaviour of the rotor are retained. This means that all the modes whose frequencies are out of range of the system bandwidth can be neglected (more in [1]).

\section{PID and PI-D control with notch filters}

To control the displacements of the flexible rotor in radial directions, two radial AMBs were employed (two control axes per each AMB). 


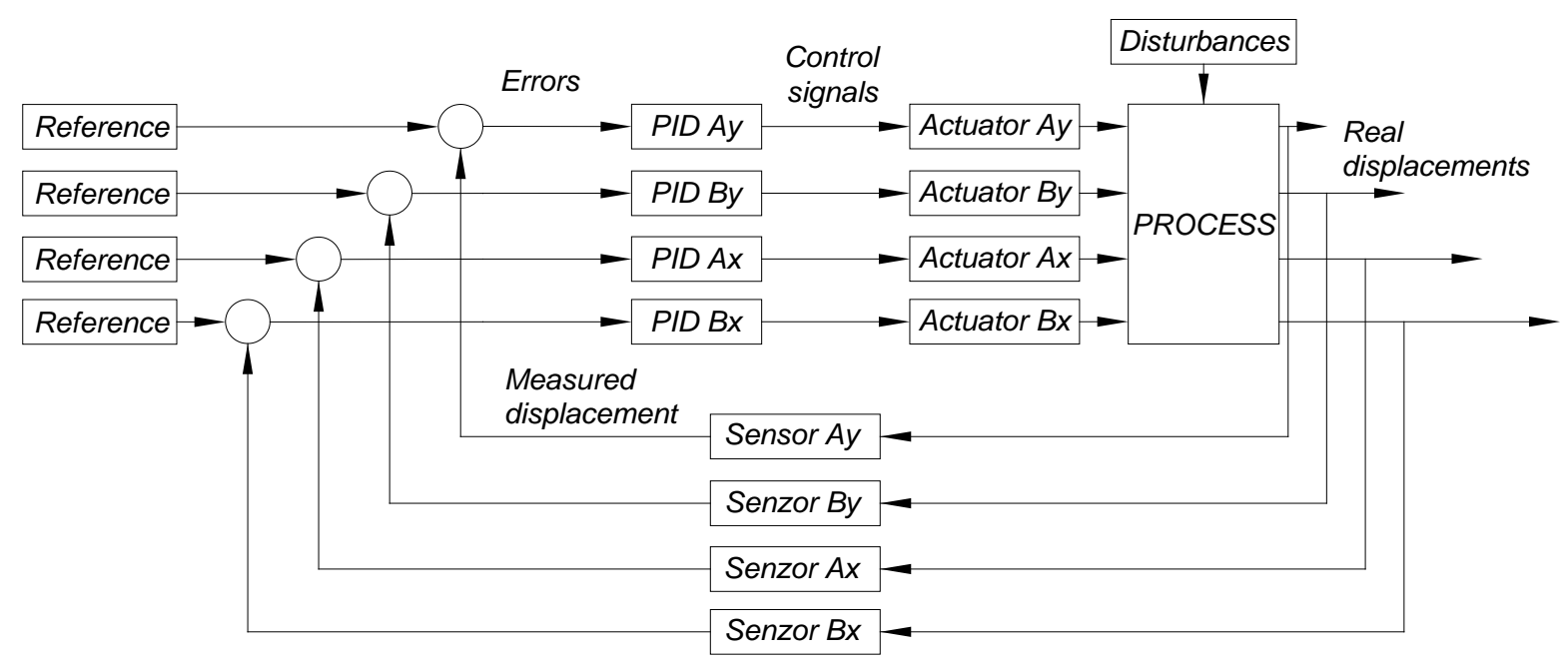

Figure 2. Magnetic bearing system with decentralised control

Although the AMB control system is inherently an MIMO (Multiple Input Multiple Output) system, it can be satisfactory modelled as four SISO (Single Input Single Output) decentralized systems, especially when dealing with PID or PI-D control systems. The magnetic bearing system with decentralised control is presented in Fig. 2.

\subsection{PID controller}

Using the standard PID control algorithm the control signal $u(t)$ can be presented as follows:

$$
\begin{gathered}
u(t)=K_{P} \cdot e(t)+K_{i} \cdot \int_{0}^{t} e(\tau) \mathrm{d} \tau \\
+K_{d} \cdot \frac{\mathrm{d} e(t)}{\mathrm{d} t}
\end{gathered}
$$

where $e(t)=r(t)-y(t)$ is the error signal, $r(t)$ is the reference signal, $y(t)$ is the measured signal, $K_{p}$ is the proportional gain, $K_{i}$ is the integral gain, $K_{d}$ is the derivate gain. It can be noticed that the error signal $e(t)$ is used to generate proportional, integral and derivate actions which are added together to generate the control signal.

In order to design the PID controller, the appropriate values for proportional, integral and derivate gains have to be determined [12]. Some researchers showed that PID controller is too sensitive for practical use [12].

\subsection{PI-D controller}

Instant discontinuities in the reference signal $r(t)$ are transmitted to the error signal $e(t)$, causing impulses in the derivative action and consequently large values of the control signal $u(t)$. Since the output signal $y(t)$ does not change instantaneously on step discontinuity, a smoother signal can be produced by taking the derivative of the output. The control strategy in which the derivative action is placed in the feedback path is known as PI-D control.

\subsection{Notch filters}

The controllers employed in the flexible rotor/AMB system include notch filters to achieve stability of the lightly damped flexible modes. A notch filter is designed as the second order standard transfer function:

$$
\begin{gathered}
G_{\text {notch }}(s)= \\
\frac{s^{2}+\omega_{\text {notch }}{ }^{2}}{s^{2}+2 \cdot \xi_{\text {notch }} \cdot \omega_{\text {notch }} \cdot s+\omega_{\text {notch }}{ }^{2}}
\end{gathered}
$$

where $\omega_{\text {notch }}$ is the central frequency and $\xi_{\text {notch }}$ is the damping ratio which controls the width of the notch in the frequency response. By implementing the notch filter, all signals are passed through, except those within a very narrow frequency range around the central frequency $\omega_{\text {notch }}$, which corresponds to some of the flexible mode frequency.

The number of notches depends on how many modes need to be attenuated. The general influence of the 
notch filter on the signal with resonant peak is shown in Fig. 3. PID and PI-D control strategies with notch filters for one control axis are presented in Fig. 4 and 5.
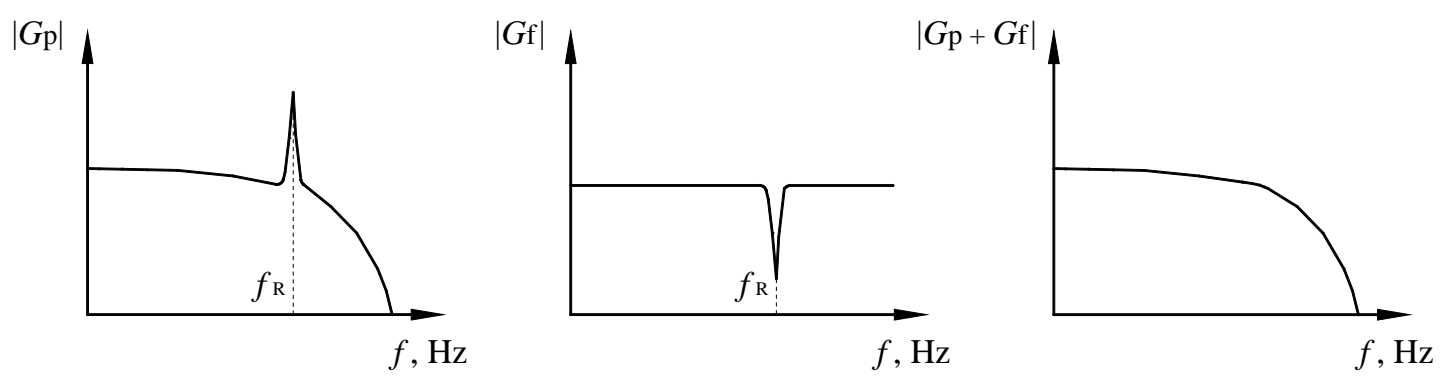

Figure 3. Frequency response of: a) the signal with resonance peak at $\omega_{\text {notch }}=2 \pi f_{R}, b$ ) the notch filter with central frequency $f_{R} c$ ) the signal with notch filter

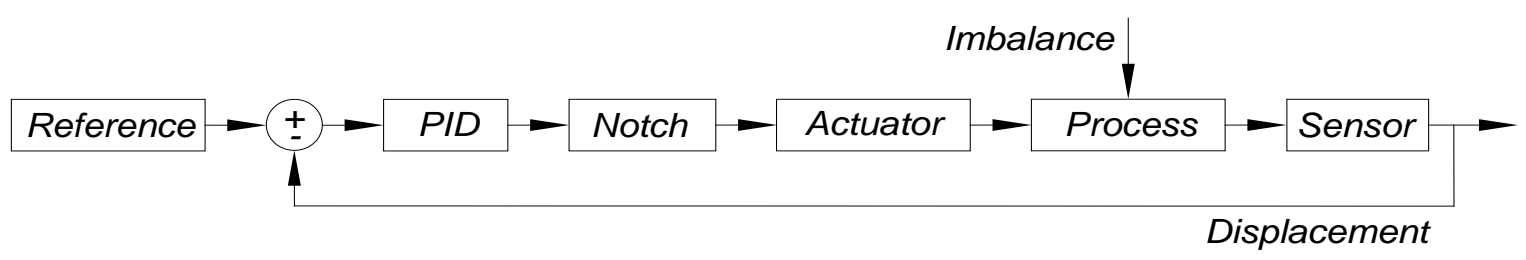

Figure 4. PID control strategy with notch filter for one control axis

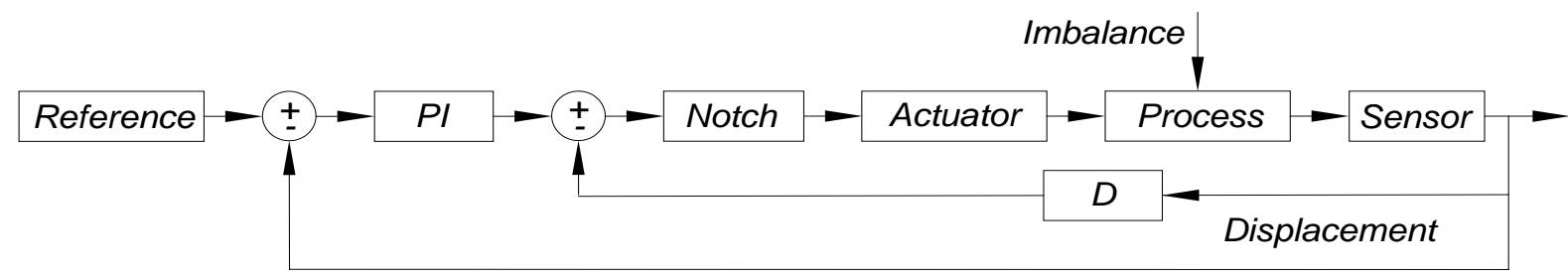

Figure 5. PI-D control strategy with notch filter for one control axis

\section{Numerical model}

The numerical model of the system is obtained in software Matlab/Simulink. Initially, the input data (state space model of the system, structural damping, the characteristics of the sensors and actuators, etc.) are prepared and defined in the form of Matlab scripts, using which the open loop model was determined. Structural damping is $2 \%, 1 \%$ and $0.5 \%$ for first, second and third form of vibration. Sensor is modelled with the sensitivity $K_{\text {sens }}=8000 \mathrm{~V} / \mathrm{m}$ and delay of $0.5 \mathrm{~ms}$ approximated by the first order Pade approximation. Actuator is modelled using second order transfer function with actuator gain $K_{a m p}=0.98 \mathrm{~V} / \mathrm{m}$, cut of frequency $f_{a m p}=$ $700 \mathrm{~Hz}$ and damping $\zeta_{a m p}=0.85$. The rotor configuration is given in Fig. 6. The grey rectangles represent the lumped masses (AMB A, AMB B, discs). The material of the rotor is standard steel with the modulus of elasticity $E=210 \mathrm{GPa}$ and with the density $\rho=7800 \mathrm{~kg} / \mathrm{m}^{3}$. The total length of the shaft is $1.1 \mathrm{~m}$ and the diameter is $0.025 \mathrm{~m}$. The mass of each disc is $2 \mathrm{~kg}$ while the mass of each AMB rotor is $8 \mathrm{~kg}$. The total mass of the rotor is $24 \mathrm{~kg}$. Using the additional data from Table 1 simulations in open loop were carried out. Obtained frequency responses were compared with the experimentally obtained open loop frequency responses. The minor existing differences were compensated in order to obtain a more accurate numerical model. More details can be found in [15]. Finally, using this open loop model the closed loop model of the entire system (including notch filters and controllers) was built in Simulink. 


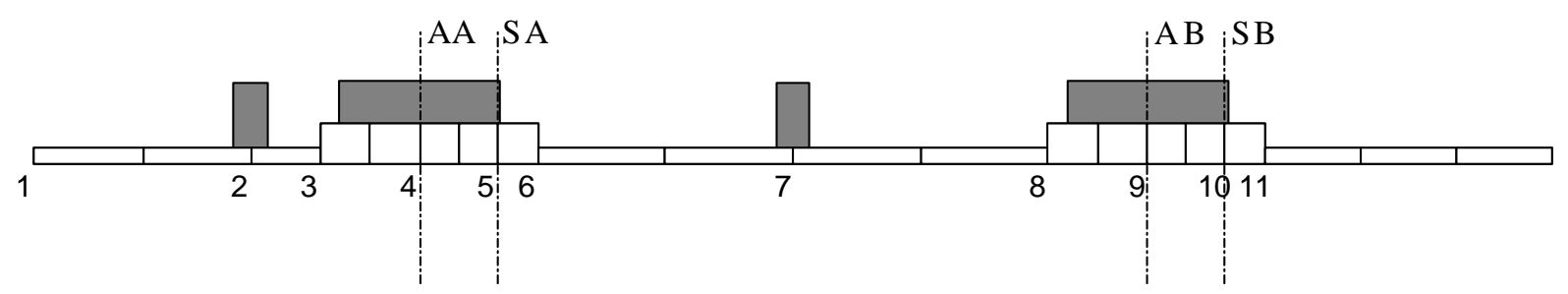

Figure 6. Rotor configuration ( $A A$ - actuator $A, S A$ - sensor $A, A B$ - actuator $B, S B$ - sensor $B$ )

Table 1. Others test rig data

\begin{tabular}{|l|c|l|c|}
\hline \multicolumn{1}{|c|}{ Name } & Value & \multicolumn{1}{c|}{ Name } & Value \\
\hline Length of laminar rotor part of AMB & $65 \mathrm{~mm}$ & Maximum inverter temperature & $100{ }^{\circ} \mathrm{C}$ \\
\hline Maximum force per one pair of poles & $1000 \mathrm{~N}$ & Maximum inverter voltage & $300 \mathrm{~V}$ \\
\hline Force-current coefficient, $k_{i}$ & $190 \mathrm{~N} / \mathrm{A}$ & Gap between rotor and safety bearings & $0.3 \mathrm{~mm}$ \\
\hline Force-displacement coefficients $k_{s}$ & $680000 \mathrm{~N} / \mathrm{A}$ & Gap between rotor and magnetic poles & $1.25 \mathrm{~mm}$ \\
\hline Coil resistance & $0.57 \Omega$ & Sensors measuring range & $0,25-1,25 \mathrm{~mm}$ \\
\hline Coil inductance & $26.48 \mathrm{mmH}$ & Sensors sensitivity & $8000 \mathrm{~V} / \mathrm{m}$ \\
\hline Maximum coil current & $10 \mathrm{~A}$ & Sensor sampling frequency & $2 \mathrm{kHz}$ \\
\hline Maximum speed of the rotor & $9000 \mathrm{rpm}$ & & \\
\hline
\end{tabular}

Since the system is symmetrical and the decentralised control was employed, the controller gains were designed only for the $y$ axis for both AMBs, and are taken to be the same for the $x$ axis. Two separate closed loop models were created; one with PID controller and the other with PI-D controller. The gains of both controllers were designed separately by using the ITAE integral criterion with optimization routine in Matlab (Matlab command fmincon), (Fig. 7) [12].

$$
J_{\mathrm{ITAE}}=\int_{0}^{t} t|e(t)| \mathrm{d} t
$$

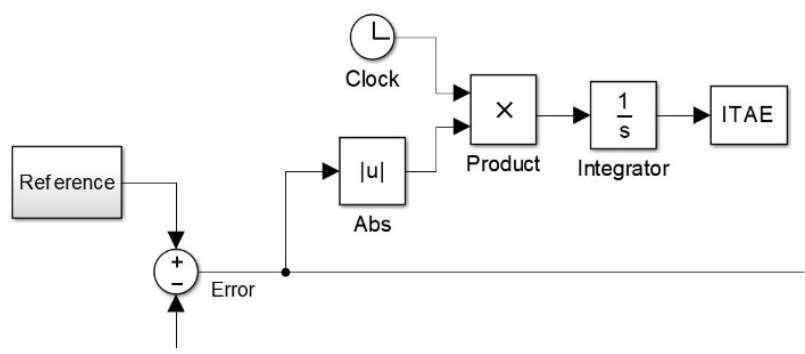

Figure 7. ITAE integral criterion implemented in Simulink

The following gains were obtained for PID controller: AMB A: $K_{p}=0.057, K_{i}=0.45, K_{d}=$ 0.00068, AMB B: $K_{p}=0.057, K_{i}=0.45, K_{d}=$ 0.00045. The gains for PI-D controller were: AMB
A: $K_{p}=0.06, K_{i}=0.95, K_{d}=0.0004$, AMB B: $K_{p}=0.043, K_{i}=0.95, K_{d}=0.00035$. Moreover, the notch filters with the central frequencies $\omega_{\text {notch } 1}=170.3 \mathrm{~Hz}$ and $\omega_{\text {notch } 2}=284.8 \mathrm{~Hz}$ were implemented per each control axis.

Finally, the simulations of the closed loop system were carried out and the performances of both systems (with PID + notch and PI-D + notch) were compared in the time and frequency domain.

\section{Performances analysis}

The performances analysis of the flexible rotor/AMB system is carried out numerically for PID + notch and PI-D + notch control. Both in time domain by observing system response to step input and in frequency domain by observing a frequency response of sensitivity function (maximum peak criteria).

\subsection{Performances analysis in time domain}

Performances analysis in time domain is carried out by observing system response to step input. Standard response to step input of a system, considers the analysis of parameters such as: rise time $t_{r}$, settling time $t_{s}$, overshoot $A$, decay ratio, and steady-state offset [16]. The rise time and settling time are measures of the speed of the response, whereas the overshoot, decay ratio and steady-state offset are 
related to the quality of the response. Figures 8 and 9 shows the responses of AMB A, in the direction of the $y$ axis, to step input applied in the amount of $0.1 \mathrm{~mm}$ in the direction of the $y$ axis on AMB A (Fig. 8, excitation and measurement on the same AMB) and in the direction of the $y$ axis on AMB B (Fig. 9, excitation on one AMB, measurement on another AMB), for the system with non-collocation. More about non-collocation of this system can be found in [15]. The responses are shown only for the $y$ axis because they are the same in the direction of the $x$ axis. Analysing the characteristics of closedloop responses shown in Fig. 8, the following conclusions can be made:

- Rise time is higher for PI-D + notch controller in comparison to PID + notch controller $(0.0032 \mathrm{~s}$ for PID and $0.0089 s$ for PI-D).

- Settling time is significantly smaller for PI-D controller ( $0.3 s$ for PID and $0.125 s$ for PI-D).

- Overshoot is larger for PI-D controller (0.108 $\mathrm{mm}$ for PID and $0.15 \mathrm{~mm}$ for PI-D).

- Steady-state offset is the same.

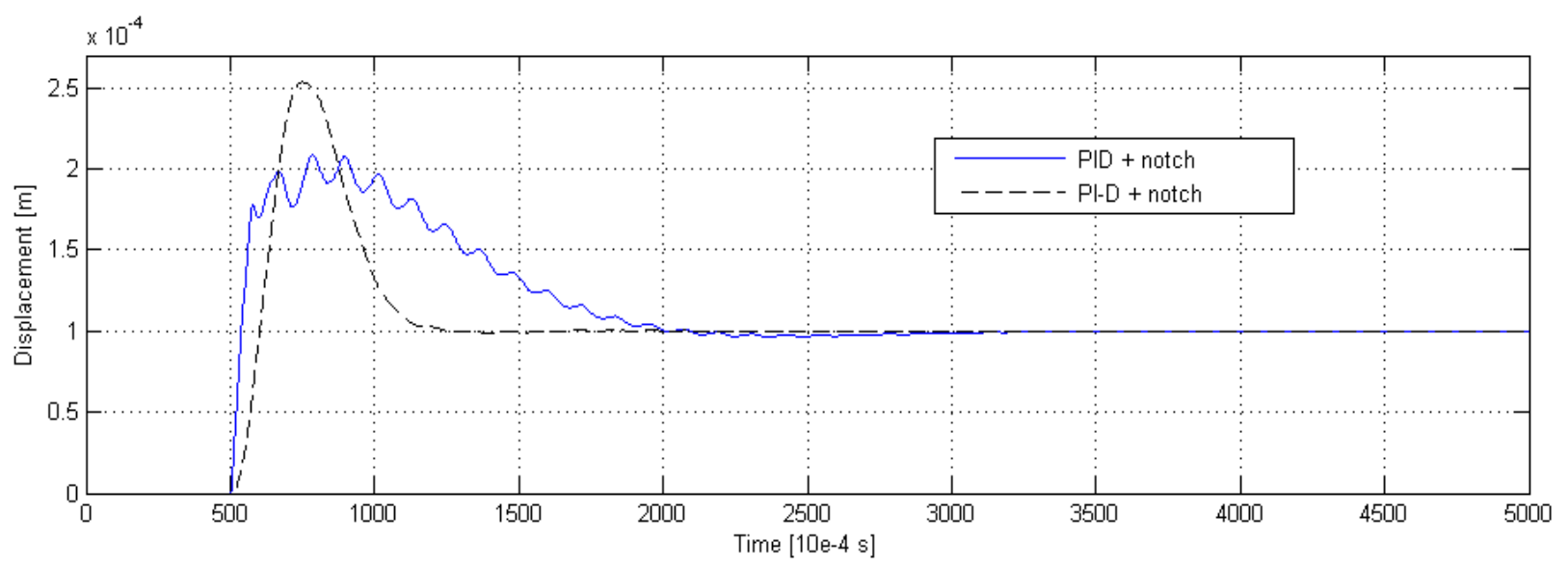

Figure 8. Response of $A M B A$, in the direction of the $y$ axis, to step in reference applied on $A M B A$, in the direction of the $y$ axis, for the system with non-collocation

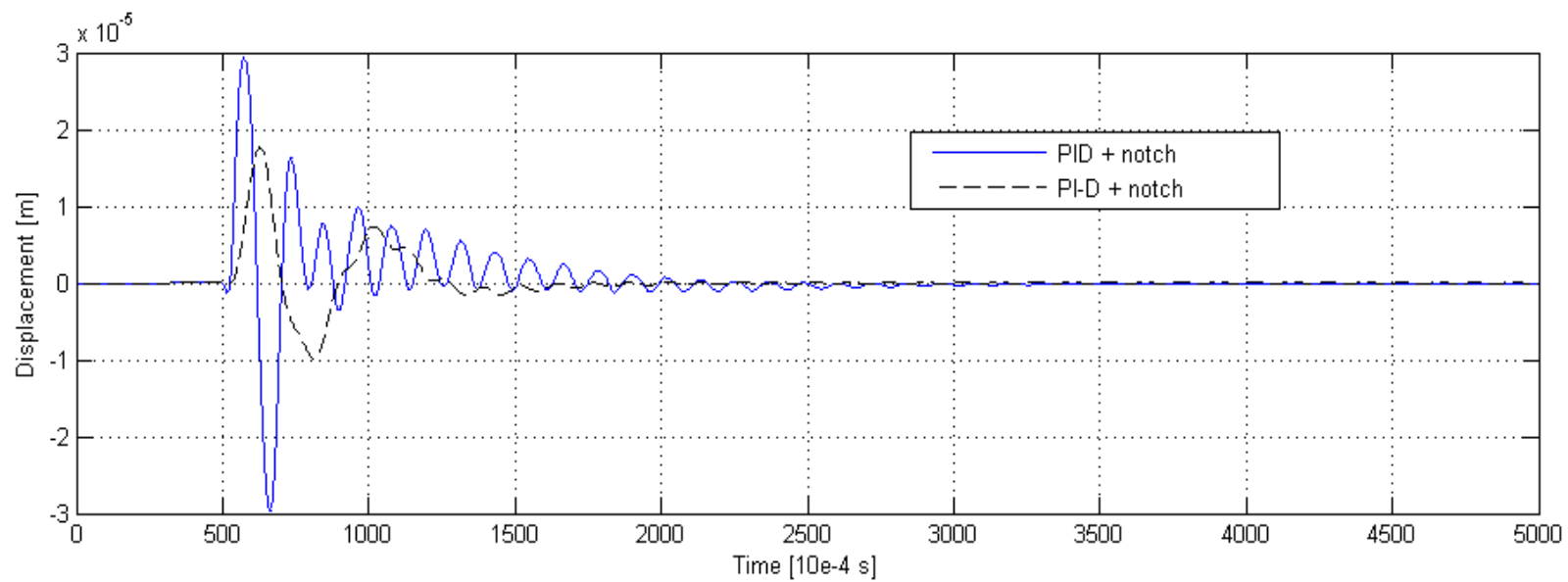

Figure 9. Response of $A M B A$, in the direction of the $y$ axis, to step in reference applied on $A M B B$, in the direction of the $y$ axis, for the system with non-collocation

It is important to notice that PI-D + notch controller gives response with much smaller oscillations in comparison to PID + notch. Analysing the characteristics of the closed-loop responses shown in Fig. 9 smaller overshoot, settling time, and oscillations can be noticed for the PI-D + notch controller.
Figures 10 and 11 shows the responses of AMB B, in the direction of the $y$ axis, to step input applied in the amount of $0.1 \mathrm{~mm}$ in the direction of the $y$ axis on AMB B (Fig. 10, excitation and measurement on the same AMB) and in the direction of the $y$ axis on AMB A (Fig. 11, excitation on one AMB, measurement on another AMB), for the system with non-collocation. 
Again, the responses are shown only for the $y$ axis because they are the same in the direction of the $x$ axis. Conclusions similar (except for overshot) to the ones for AMB A can be made for AMB B as well:

- Rise time is higher for PI-D + notch controller in comparison to PID + notch controller $(0.0033 \mathrm{~s}$ for PID and $0.0052 s$ for PI-D).

- Settling time is significantly smaller for PI-D + notch controller ( $0.35 \mathrm{~s}$ for PID and $0.2 \mathrm{~s}$ for PID).

- Overshoot is smaller for PI-D + notch controller (0.082 $\mathrm{mm}$ for PID and $0.07 \mathrm{~mm}$ for PI-D).
- Steady-state offset is the same.

Yet again, it is important to notice that PI-D + notch controller gives response with much smaller oscillations. Analysing the characteristics of the closed-loop responses shown in Fig. 11 smaller overshoot, settling time, and oscillations can be noticed for PI-D + notch controller. The analysis in time domain showed that shifting derivative action from main branch of the system to feedback loop improved performance characteristic of the flexible rotor/AMB system with non-collocation.

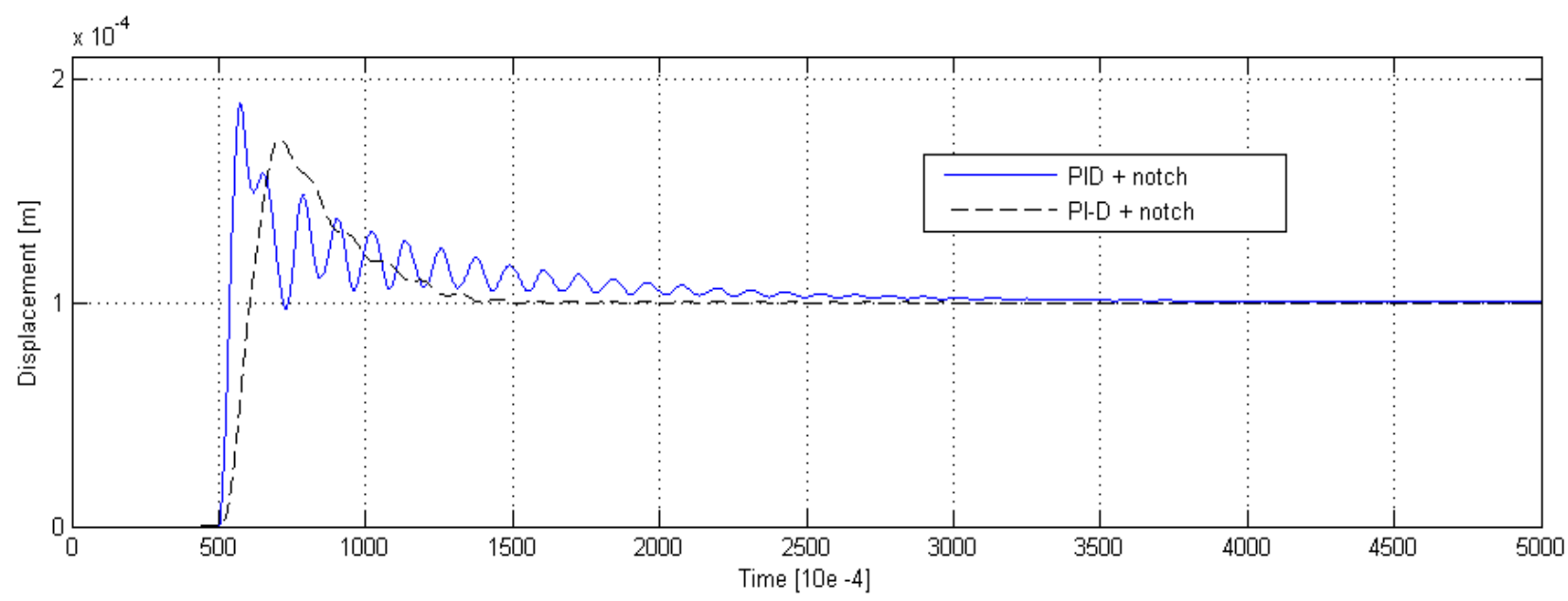

Figure 10. Response of $A M B B$, in the direction of the $y$ axis, to step in reference applied on $A M B B$, in the direction of the $y$ axis, for the system with non-collocation

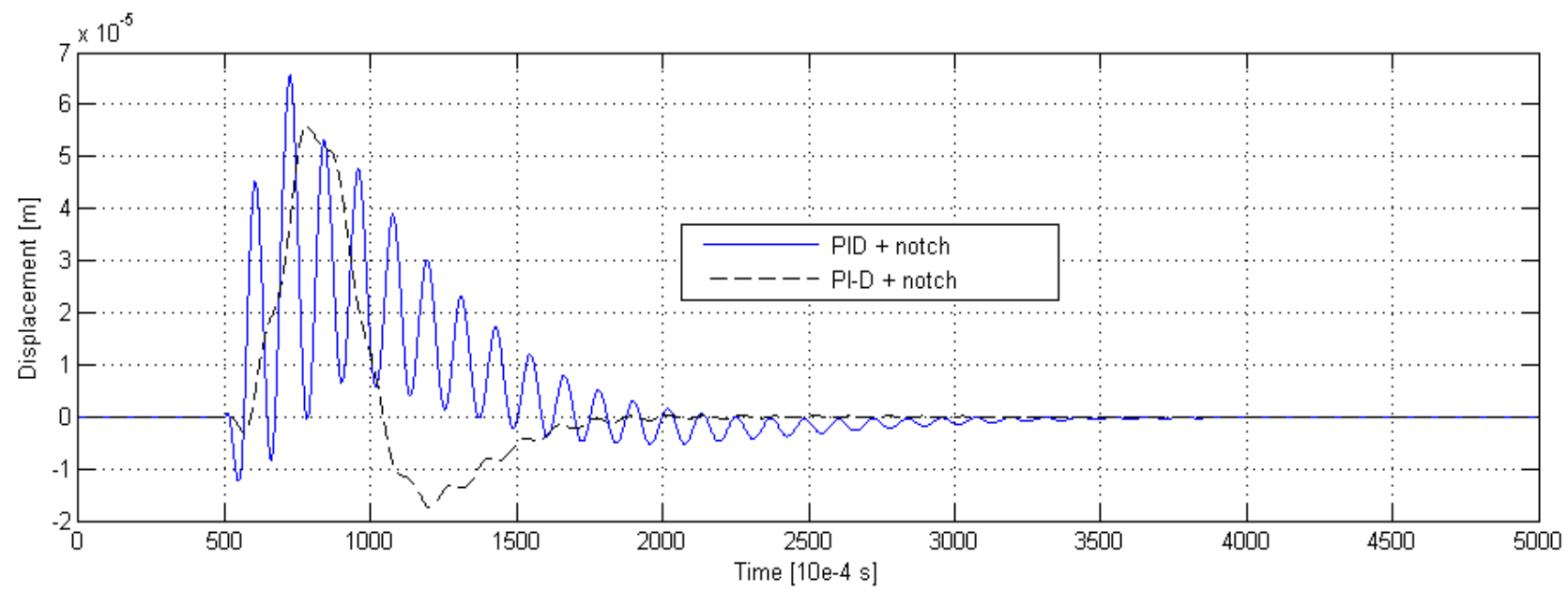

Figure 11. Response of $A M B B$, in the direction of the $y$ axis, to step in reference applied on $A M B A$, in the direction of the $y$ axis, for the system with non-collocation 


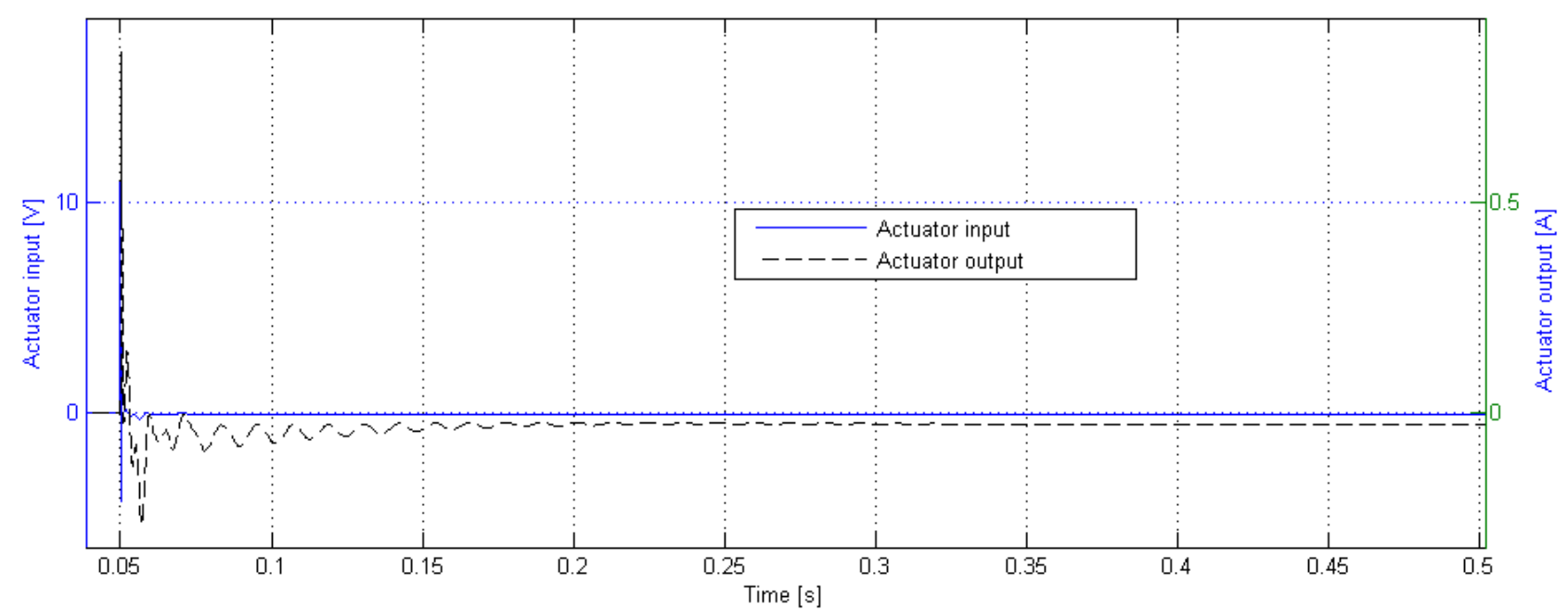

Figure 12. Actuator output and input signal of AMB A for PID + notch control, in the direction of the $y$ axis, to step in reference applied on $A M B A$, in the direction of the $y$ axis, for the system with noncollocation

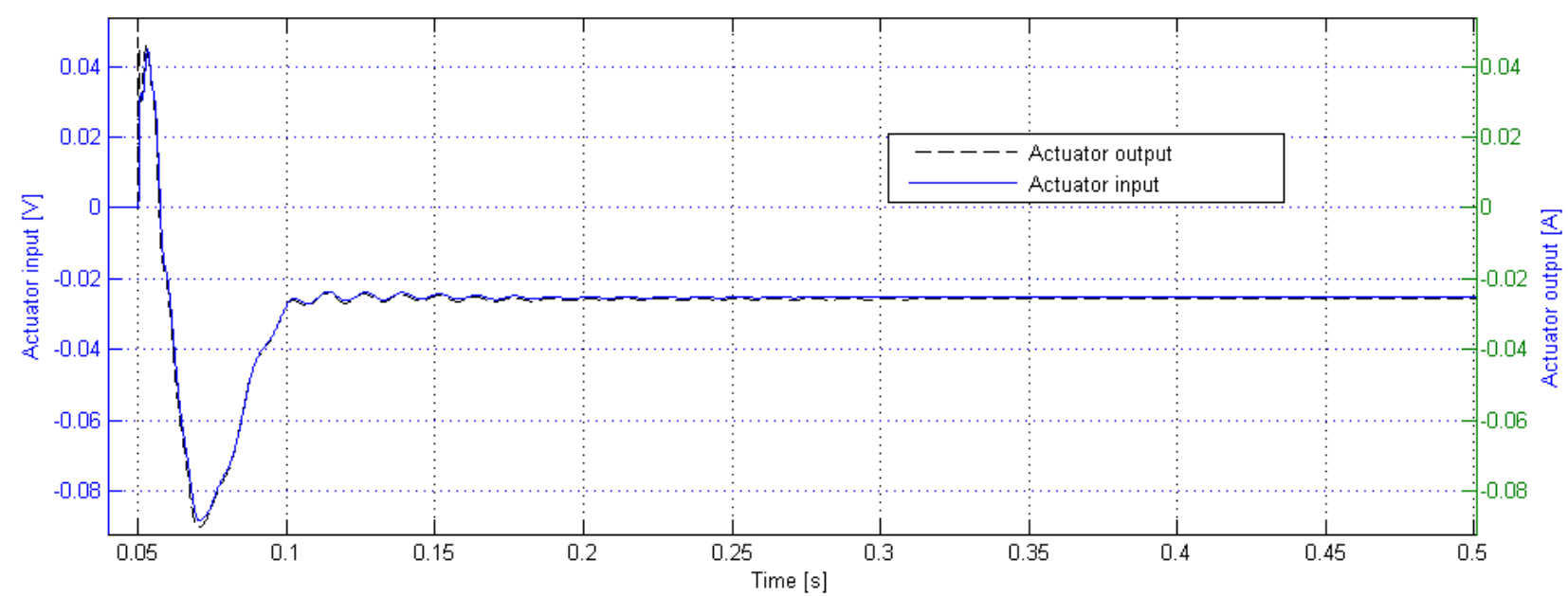

Figure 13. Actuator output and input signal of AMB A for PI-D + notch control, in the direction of the $y$ axis, to step in reference applied on $A M B A$, in the direction of the $y$ axis, for the system with noncollocation

Figures 12 and 13 show actuator output and input signal of AMB A with PID + notch (Fig 12) and PI$\mathrm{D}+$ notch (Fig. 13) control in the direction of the $y$ axis, when step in reference is applied on AMB A, in the direction of the $y$ axis, for the system with noncollocation. It can be noticed that integrator wind-up effect does not appear, so anti wind-up scheme is not applied. Similar results can be obtained for AMB B. Actuator output and input signals have steady state values below zero because this are the values before current for weight compensation is added to the output signal.

\subsection{Performances analysis in the frequency domain}

The frequency-response of the open loop transfer function $L$, sensitivity function $S$ and complementary sensitivity function $T$ can be used to analyse performances of a closed loop system.

The advantage of the frequency domain, compared to step response analysis, is that it considers a broader class of signals (sinusoids of any frequency). This makes it easier to characterize feedback properties, and system behaviour in the crossover (bandwidth) region.

The most important characteristic, for sensitivity analysis of the system, which can be obtained in the 
frequency domain and which is used in this research, is the value of the maximum peak of the sensitivity function, also known as Maximum peak criteria.

Sensitivity function is defined as:

$$
S=\frac{1}{(1+\mathrm{G} \cdot \mathrm{C})},
$$

where $G$ is transfer function of the system and $C$ is transfer function of the controller. The maximum peak of the sensitivity function are defined as:

$$
M_{\mathrm{S}}=\max _{\omega}|S(j \omega)|
$$

When measuring the open-loop transfer function of one control axis, all of the control axes are closed loops. By repeating this measurement step by step for each control axis, a set of the open-loop transfer functions is measured and transferred to sensitivity functions. Otherwise, each sensitivity function is directly measured (according to ISO 14839-3). In this research, two sensitivity functions are obtained for two axis control system and they are directly measured at rotor standstill. Typically, it is required that $M_{\mathrm{S}}$ is small, as close to 1 as possible (less than: $9.5 \mathrm{~dB}$ for zone A, $12 \mathrm{~dB}$ for zone $\mathrm{B}, 14 \mathrm{~dB}$ for zone $\mathrm{C}$, and more than $14 \mathrm{~dB}$ for zone $\mathrm{D}$ according to ISO 14839-3). The definition of each stability zone is determined by adapting the guidelines of ISO7919-1.

- Zone A: The sensitivity functions of newly commissioned machines.

- Zone B: Machines with the sensitivity functions within this zone are normally considered acceptable for unrestricted long-term operation.

- Zone C: Machines with the sensitivity functions within this zone are normally considered unsatisfactory for long-term continuous operation. Generally, the machine may be operated for a limited period in this condition until a suitable opportunity arises for remedial action.
- Zone D: Considered to be sufficiently severe to cause damage to the machine.

Figure 14 shows the frequency-response of the system sensitivity function from the actuator at AMB $\mathrm{A}$ in the direction of the $y$ axis to the sensor at AMB $\mathrm{A}$ in the direction of the $y$ axis. The values of the maximum peaks of the sensitivity functions are indicated. It can be noticed that PI-D + notch controller has a lower value of $M_{S}$ (for PID + notch $M_{s}=11.2$, for PI-D + notch $\left.M_{s}=6.27\right)$. It can be concluded that PI-D + notch controller has a better performance (zone A according to ISO 14839-3) compared to PID + notch controller (zone B according to ISO 14839-3). Fig 15 shows the frequency-response of the system sensitivity function from the actuator at AMB B in the direction of the $y$ axis to the sensor at AMB B in the direction of the $y$ axis. Again, it can be noticed that PI-D + notch controller has a lower value of $M_{S}$ (for PID + notch $M_{s}=15$, for PI-D + notch $M_{s}=10.09$ ). In this case, $\mathrm{PID}+$ notch controller is inside the zone $\mathrm{D}$ according to ISO 14839-3, and PI-D + notch fits inside the zone B. The system's overall rating is determined as the worst rating of any of the transfer functions measured. In this research, there are two sensitivity transfer functions (Fig. 14 and Fig. 15). According to overall rating, PID + Notch controller fits inside zone $\mathrm{D}$ according to ISO 14839-3, and PI-D + Notch fits inside zone B according to ISO 14839-3, which is a significant improvement. Frequency domain analysis showed that shifting derivative action from the main branch of the system to feedback loop improved performance characteristic of the flexible rotor/AMB system with non-collocation. Frequency analysis showed that sensitivity of the system can be improved significantly. PI-D + notch controller can replace the standard PID + notch controller in cases where a fast response and a response without oscillations are needed. 


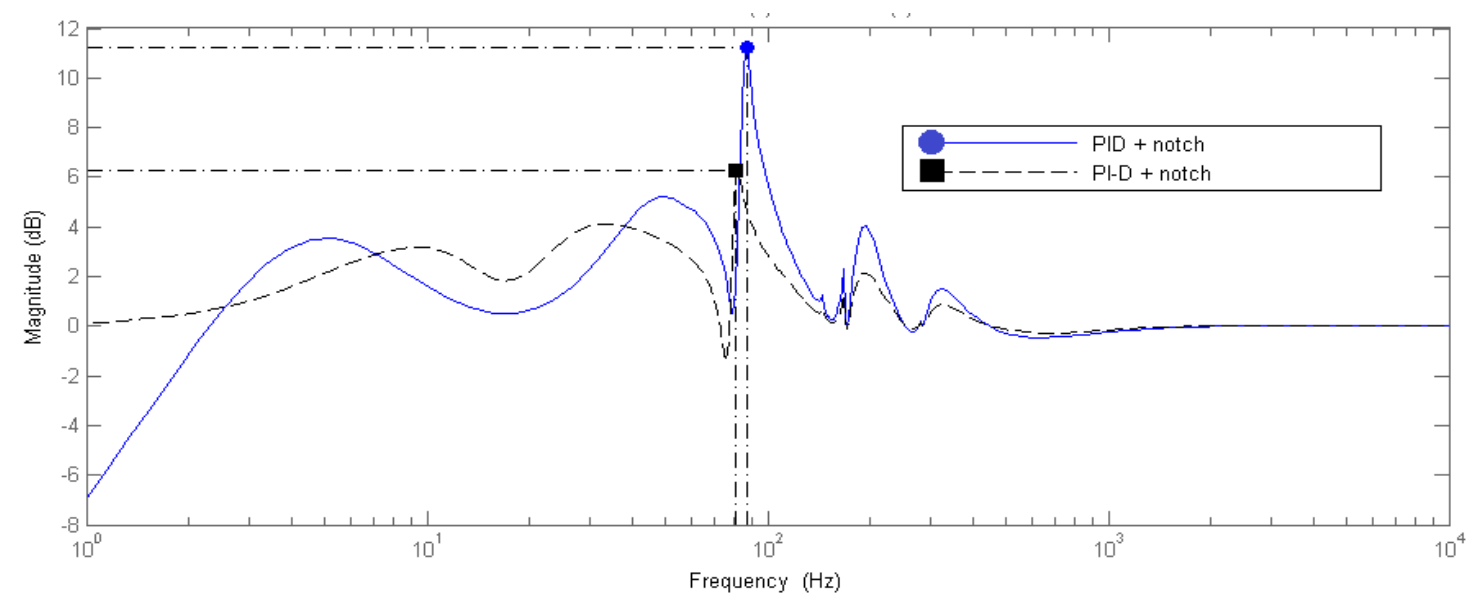

Figure 14. Frequency-response of the system sensitivity function from the actuator at AMB A in the direction of the $y$ axis to the sensor at $A M B A$ in the direction of the $y$ axis

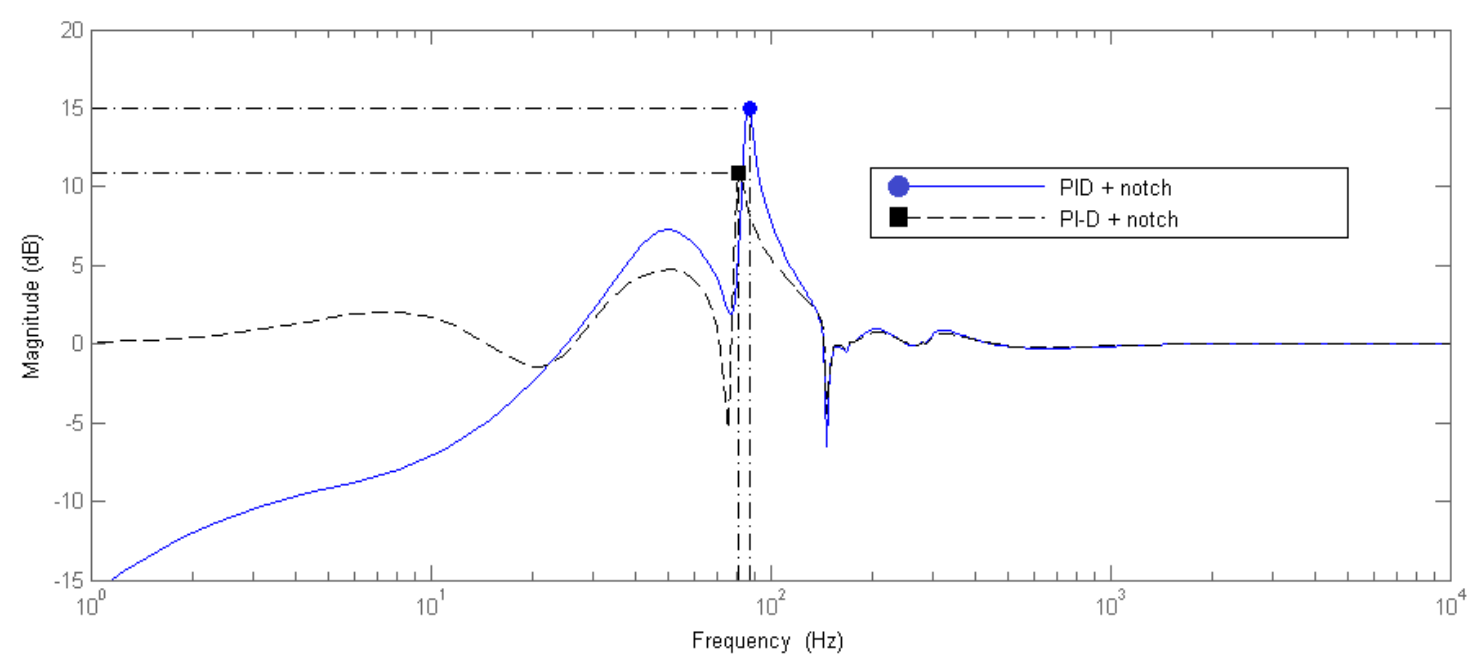

Figure 15. Frequency-response of the system sensitivity function from the actuator at $A M B B$ in the direction of the $y$ axis to the sensor at $A M B B$ in the direction of the $y$ axis

\section{Conclusion}

Through this research, the performances of the flexible rotor/AMB system are investigated in a case of PID and PI-D control, both in combination with notch filters. The performances of the system are analysed in the time domain by observing system response to step input and in the frequency domain by observing a frequency response of the sensitivity function. PID control in combination with notch filters is the most common control strategy to control flexible rotors using AMB. This paper proves that the performance of such control system can be improved using a PI-D + notch controller. From the time domain analysis, smaller overshoot (except for one measurement), settling time and oscillations can be noticed for PI-D + notch controller. Frequency domain analysis showed that flexible rotor/AMB system with PI-D + notch controller is less sensitive in comparison to the system with standard PID + notch controller.

\section{Acknowledgement}

This work has been supported in part by the University of Rijeka under the project number uniritehnic-18-225.

\section{References}

[1] Schweitzer, G.: Stabilization of self-excited rotor vibrations by an active damper, In Dynamics of Rotors (ed. F. I. Niordson), Springer-Verlag, Berlin, 1974. 
[2] Losch, F.: Identification and automated Controller Design for Active Magnetic Bearing Systems, PhD Thesis, Swiss Federal Institute of Technology, ETH Zurich, 2002.

[3] McCallun, D.C.: Dynamic modelling and control of a magnetic bearing suspended rotor system, Master Thesis, Massachusetts Institute of Technology, 1988.

[4] Salm, J., Schweitzer, G.: Modeling and control of a flexible rotor with magnetic bearings, Conference Proceedings on Third International Conference on Vibrations in Rotating Machinery, New York, September, 1984, 553 - 561.

[5] Bleuler, H.: Decentralized Control of Magnetic Rotor Bearing Systems, PhD Thesis, No. 7573, ETH Zurich, Switzerland, 1984.

[6] Larsonneur, R.: Design and Control of Active Magnetic Bearing Systems for High Speed Rotation, Ph.D. thesis, Swiss Federal Institute of Technology, ETH Zurich, 1990.

[7] Gähler, G.: Rotor Dynamic Testing and Control with Active Magnetic Bearings, $\mathrm{PhD}$ Thesis, No. 12718, ETH Zurich, Switzerland, 1998.

[8] Bratland, M., Hauden, B., Rolvag, T.: Modal analysis of active flexible multibody systems, Computers and Structures, 89 (2011), 750761.

[9] Jastrzebski, R. P., Hynynen, K. M., Smirnov, A.: $H_{\infty}$ control of active magnetic suspension, Mechanical Systems and Signal Processing, 24 (2010), 995-1006.
[10] Štimac, G., Braut, S., Žigulić, R.: Vibration suppression of flexible rotor using active magnetic bearings (AMB), Transactions of Famena, 35 (2011), 3, 27-38.

[11] Inayat-Hussain, J. I.: Nonlinear dynamics of a statically misaligned flexible rotor in active magnetic bearings, Commun. Nonlinear Sci. Numer. Simulat., 15 (2010), 764-777.

[12] Štimac, G.: Aktivno smanjenje vibracija kod rotacijskih strojeva, $\mathrm{PhD}$ Thesis, University of Rijeka, Faculty of engineering, Croatia, 2012.

[13] Wei, C. S., Soffker, D.: Optimization Strategy for PID-Controller Design of AMB Rotor Systems, IEEE Transactions on Control Systems Technology, 24 (2016), 3, 788-803.

[14] Noshadi, A., Shi, J., Lee, W. S., Shi, P., Kalman, A.: Optimal PID-type fuzzy logic controller for a multi-input multi-output active magnetic bearing system, Neural Computing \& Applications, 27 (2016), 7, 2031-2046.

[15] Štimac, G., Braut, S., Bulić, N., Žigulić, R.: Modeling and experimental verification of a flexible rotor/AMB system, COMPEL - The International Journal for Computation and Mathematics in Electrical and Electronic Engineering, 32 (2013), 4, 1244-1254.

[16] Skogestad, S., Postlethwaite, I.: Multivariable feedback control, John Wiley \& Sons, Chichester, UK, 1996. 